\title{
A Randomized Control Trial of 3 IU IV Oxytocin Bolus with 7 IU Oxytocin Infusion versus 10 IU Oxytocin Infusion During Cesarean Section for Prevention of Postpartum Hemorrhage
}

This article was published in the following Dove Press journal:

International Journal of Women's Health

\author{
Rajasri G Yaliwal (D' \\ Aruna M Biradar (1) \\ Prathibha S Dharmarao $\mathbb{D D}^{2}$ \\ Shreedevi S Kori (iD) \\ Subhashchandra R Mudanur (D) \\ Neelamma G Patil (iD) \\ Shobha S Shiragur (D) \\ Sangamesh S Mathapati (iD) \\ 'Department of OBGYN, BLDE (DU) \\ Shri B. M. Patil Medical College Hospital \\ and Research Center, Vijayapura, \\ Karnataka, India; ${ }^{2}$ Department of \\ Anesthesiology, BLDE (DU) Shri \\ B. M. Patil Medical College Hospital and \\ Research Center, Vijayapura, Karnataka, \\ India
}

Purpose: Oxytocin is the preferred choice for prophylaxis and treatment of postpartum hemorrhage. Intravenous infusion has been a widely accepted route for Oxytocin administration. However, intravenous bolus route is not a readily preferred route due to apprehensions regarding hypotension that it may cause. This trial compares low dose 3 IU intravenous (IV) bolus Oxytocin along with 7 IU Oxytocin in intravenous infusion to 10IU Oxytocin intravenous infusion during cesarean section.

Patients and Methods: A total of 250 term pregnant women were randomized to either 3 IU intravenous bolus with 7 IU intravenous infusion of Oxytocin or 10IU of intravenous Oxytocin infusion. The difference in pre- and post-operative hemoglobin levels, tone of the uterus, hemodynamic changes, adverse effects of the drug, need for additional uterotonics and need for blood transfusions were assessed.

Results: There was $6.7 \%$ less blood loss in the 3 IU IV bolus Oxytocin with 7 IU Oxytocin infusion group in comparison to the Oxytocin infusion group. The tone of the uterus was firmer in IV bolus Oxytocin with Oxytocin infusion group at 5 minutes $(p<0.001)$ than the Oxytocin infusion group. There was no significant difference in the hemodynamic changes, adverse effects or need for blood transfusions.

Conclusion: Intravenous bolus of 3 IU Oxytocin along with 7 IU infusion of Oxytocin is as safe and more effective than intravenous infusion of $10 \mathrm{IU}$ of Oxytocin during cesarean section in the prevention of postpartum hemorrhage.

Keywords: Oxytocin, cesarean section, blood loss, hemoglobin, uterine tone

\section{Introduction}

Primary postpartum hemorrhage $(\mathrm{PPH})$ is one of the leading causes of maternal morbidity and mortality worldwide. The most common cause of primary $\mathrm{PPH}$ is uterine atony. Atonic PPH rates are increasing in developed countries despite routine active management of the third stage of labor. In lessdeveloped countries; primary PPH remains the leading cause of maternal death. ${ }^{1}$

Various uterotonics have been used over the years. Oxytocin, Ergometrine, Misoprostol and PGF2-alpha have been extensively studied. However, the optimal route and dose of these drugs are still being investigated. Oxytocin induces superior myometrial contractions compared to Ergonovine, PGF2 $\alpha$, and Misoprostol. The
Correspondence: Aruna M Biradar Rajasri G Yaliwal

Department of OBGYN, BLDE (DU) Shri B.M. Patil Medical College, Hospital and Research Center, Vijayapura, Karnataka, India

Tel +91 $8197191472 ;+919845152240$

Fax +91 8352263303

Email aruna.biradar@bldedu.ac.in;

ryaliwal@bldedu.ac.in
International Journal of Women's Health 2020:12 1091-1097 
effect of Oxytocin is reduced in myometrium of women with Oxytocin-augmented labor; however, it is still superior to the other uterotonics. ${ }^{2,3}$

Various routes and doses of Oxytocin have been studied. Ten IU Intramuscular injection, $10 \mathrm{IU}$ intravenous infusion, and10 IU intravenous bolus of Oxytocin in the third stage of labor for prevention of postpartum hemorrhage have been used. Clinical effects may differ if intravenous Oxytocin is delivered via bolus push or over a longer duration via dilute infusion. While there is some evidence that the more immediate, higher concentration of bolus delivery could lead to a stronger effect on uterine contractions, this route is less frequently used due to fear of hypotension, although this problem has only been noted in case studies of women under general anesthesia during caesarean section. In a largescale study conducted in Egypt, it was observed that in comparison to10 IU Oxytocin IM injection, the mean blood loss was $5.9 \%$ less with 10 IU IV infusion and $11.1 \%$ less with $10 \mathrm{IU}$ IV bolus Oxytocin when used as prophylaxis during vaginal delivery. ${ }^{4}$ Other studies have shown that $5 \mathrm{IU}$ of Oxytocin IV bolus was as effective as $10 \mathrm{IU}$, with lesser variation in the heart rate and blood pressure when used during cesarean section. ${ }^{5}$ Doses of 3 IU bolus have been studied and have shown to be as effective as the 10 IU intravenous bolus doses of Oxytocin with fewer adverse effects. ${ }^{6}$ Although the value of routine oxytocics to reduce postpartum hemorrhage after vaginal birth has been well established, their value in caesarean section has received little attention. ${ }^{7}$ It has been assumed that the benefits of oxytocics observed at vaginal birth also apply to caesarean section. ${ }^{8,9}$ The guidelines of the Royal College of Obstetricians and Gynecologists (UK) on caesarean section recommend a slow intravenous bolus dose of 5 IU of Oxytocin after delivery of the baby. ${ }^{10}$ This dose is based on the principles of active management of the third stage of labor. ${ }^{11-13}$ Similar practices are followed across most of Europe and Australia. ${ }^{14}$ The route of Oxytocin has been studied by various researchers. IV infusion of Oxytocin has been preferred during cesarean section as an IV line would have been secured and it has faster plasma peak concentration as in comparison to the IM route. ${ }^{15-17} \mathrm{IV}$ bolus Oxytocin has been associated with a faster peak plasma concentration of Oxytocin and faster uterine contraction however, it has been associated with sudden hypotension as well. Hypotension during cesarean section has been associated with higher dosages of Oxytocin. It has also been observed when IV bolus Oxytocin was administered during cesarean section when general anesthesia was used. ${ }^{18}$

This study aimed to compare a lower dose of $3 \mathrm{IU}$ Oxytocin bolus along with 7 IU Oxytocin infusion with a standard dose of 10 IU Oxytocin infusion during cesarean section.

\section{Patients and Methods}

Study Setting: The study participants were pregnant women admitted to the labor ward at the Department of Obstetrics and Gynecology, BLDE (Deemed to be University) Shri B.M. Patil Medical College, Hospital and Research Centre, Vijayapura, Karnataka, India.

\section{Sample Size Calculation}

As per previous studies, 250 (125 per group) patients were required to participate in the study to have a $90 \%$ chance of detecting as significant (at the $5 \%$ level), a decrease in the mean blood loss $(\mathrm{mL})$ from $456 \pm 350$ in the group I to $600 \pm 350$ in the group II. ${ }^{18,19}$

This calculation was based on the formula:

$$
n=f 3(\alpha / 2, \beta) \times 2 \times \sigma^{2} /\left(\mu_{1}-\mu_{2}\right)^{2}
$$

where $\mu 1$ and $\mu_{2}$ are the mean outcomes in the study groups, respectively, and $\sigma$ is the standard deviation.

All consenting women with a pregnancy of term gestation undergoing cesarean section (Emergency or Elective) were included in the study. Women with a history of severe anemia, coagulopathies, cardiac, hepatic, renal diseases, known conditions predisposing to atonic PPH like hydramnios, multiple gestation prolonged labor, severe pre-eclampsia, eclampsia, women exposed to oxytocics in labor, women requiring General anesthesia, women with a previous history of rupture were excluded from the study.

\section{Methodology}

The study was conducted in the Department of Obstetrics and Gynecology, Shri B.M. Patil Medical College Hospital and Research Center, Vijayapura Karnataka, India from 25th February 2020 to 27th April 2020. The hospital is the main tertiary care center for the district of Vijayapura. A total of 250 term pregnant women admitted to the labor ward of the hospital fulfilled the inclusion criteria and were included in the study. Written and informed consent was obtained from all participants. A detailed history and clinical findings were recorded in the prescribed proforma. 
The cesarean sections were done by consultant obstetricians of the Department of OBGYN, BLDE (DU) Shri BM Patil Medical College, Hospital and Research Center. Preoperative complete blood count (CBC) and post-operative complete blood count were done. The pre-operative hemoglobin level was taken within 24 hours of conducting the cesarean section and post-operative hemoglobin was done 48 hours after the surgery was done. The blood samples for $\mathrm{CBC}$ were taken prior to starting any IV fluids pre- operatively and 48 hours post-operatively making sure that there was more than 12-hour duration from the last IV fluid before drawing the blood sample.

\section{Study Design}

Single Blinded Randomized Controlled Parallel-Group Trial

The study has taken ethical clearance from the Institutional Ethics Committee BLDE (Deemed to be University). Ref

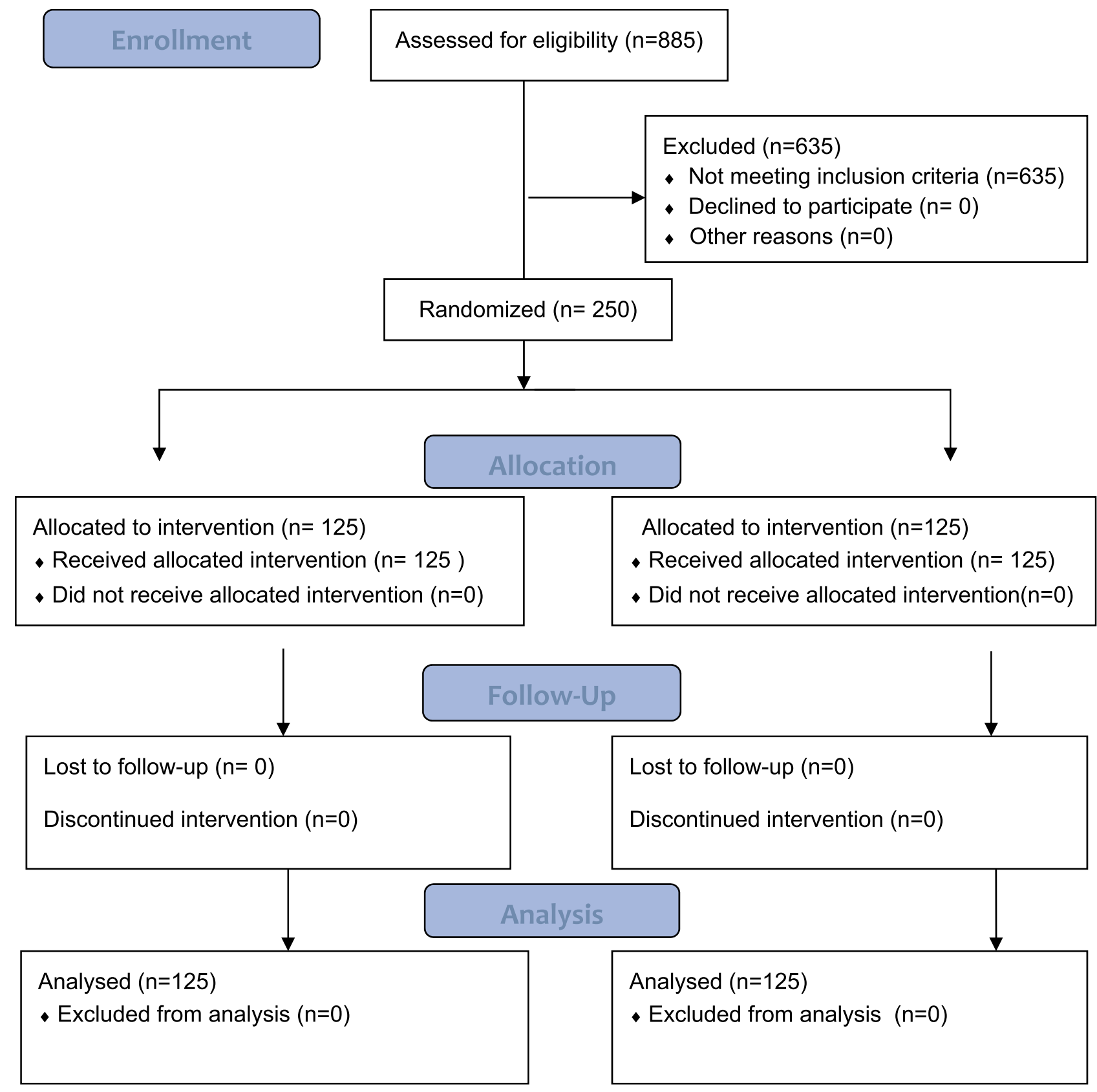

Figure I CONSORT flow diagram.

Note: https://journals.plos.org/plosmedicine/article id=10.1371/journal.pmed.100025ICitation: Schulz KF, Altman DG, Moher D, for the CONSORT Group (20I0) CONSORT 2010 Statement: Updated Guidelines for Reporting Parallel Group Randomised Trials. PLoS Med 7(3): el00025I.Copyright: (C) 20I0 Schulz et al. Creative Commons Attribution License. ${ }^{19}$ 
Table I Comparison of Age, Duration of Married Life and Period of Gestation Between Group I and Group 2

\begin{tabular}{|l|l|l|l|l|l|}
\hline \multirow{2}{*}{ Parameters } & \multicolumn{2}{|l|}{ Group I } & \multicolumn{2}{l|}{ Group 2 } & \multirow{2}{*}{ P value* } \\
\cline { 2 - 5 } & Mean & SD & Mean & SD & \\
\hline Age (yrs) & 24.0 & 3.7 & 24.2 & 3.9 & 0.766 \\
Duration of married life & 4.6 & 3.6 & 4.6 & 3.5 & 0.957 \\
Period of gestation & 38.8 & 2.4 & 38.8 & 1.8 & 0.936 \\
\hline
\end{tabular}

Note: *If the p-value is equal to or lesser than 0.05 then the result is considered to be statistically significant.

Table 2 Comparison of Parity Between Group I and Group 2

\begin{tabular}{|l|l|l|l|l|l|}
\hline \multirow{2}{*}{ Parity } & \multicolumn{2}{|l|}{ Group I } & \multicolumn{2}{l|}{ Group 2 } & \multirow{2}{*}{ P value* } \\
\cline { 2 - 5 } & N & $\%$ & N & $\%$ & \\
\hline 0 & 50 & $40.0 \%$ & 45 & $36.0 \%$ & \multirow{2}{*}{0.695} \\
1 & 47 & $37.6 \%$ & $5 \mathrm{I}$ & $40.8 \%$ & \\
2 & 27 & $21.6 \%$ & 26 & $20.8 \%$ & \\
3 & $\mathrm{I}$ & $0.8 \%$ & 3 & $2.4 \%$ & \\
Total & 125 & $100.0 \%$ & 125 & $100.0 \%$ & \\
\hline
\end{tabular}

Note: *If the p-value is equal to or lesser than 0.05 then the result is considered to be statistically significant.

NO.354-/2019-2020. The study was conducted in accordance with the Declaration of Helsinki.

\section{Registration Number at Clinical Trials Registry - India: CTRI/2020/02/023583}

The participants were divided into two groups of 125 participants each by computerized randomization obtained from the website www.randomization.com

All participants were given spinal anesthesia with Inj. Bupivacaine $(0.5 \%)$ along with Inj Buprenorphine $60 \mathrm{mcg}$. None of the patients received epidural anesthesia or general anesthesia.

\section{Group I: 3 IU IV Oxytocin Bolus with 7 IU Oxytocin} in IV Infusion

3 IU of Oxytocin was diluted and administered intravenously over 1 minute. 7 IU units of Oxytocin was added to the IV fluid. The drug was given to the mother at the delivery of the anterior shoulder of the baby. The IV fluid used was Ringer's Lactate or $0.9 \%$ Normal Saline. The IV fluid with Oxytocin was infused at the drip rate of $60 \mathrm{drops} / \mathrm{min}$.

\section{Administration of 3 IU IV Bolus Oxytocin}

$$
1 \mathrm{ml} \text { Oxytocin }=5 \mathrm{IU}
$$

This $1 \mathrm{~mL}$ was diluted with $4 \mathrm{~mL}$ of $0.9 \%$ normal saline making it $1 \mathrm{IU}$ per $\mathrm{mL} .3 \mathrm{~mL}$ was given bolus and $2 \mathrm{~mL}$ was given in IV infusion along with another 5 IU of Oxytocin.

\section{Group II}

10 IU Oxytocin was added to the intravenous infusion. The IV fluid with Oxytocin was infused at the rate of 60 drops/minute. IV fluid used was Ringer's Lactate or $0.9 \%$ Normal Saline.

\section{Primary Outcome}

Assessment of blood loss: This was done by calculating the pre- and post-operative hemoglobin levels. As blood loss during surgery may be difficult to assess, a difference in the pre and post-operative hemoglobin levels was calculated to estimate the blood loss.

\section{Secondary Outcome}

The following were assessed: The heart rate, systolic blood pressure, diastolic blood pressure SPO2 and ECG lead recordings were recorded just before the intervention and then at 1,5,10 minutes and at the end of the procedure. These parameters were recorded on a monitor by the anesthesiologist.

Tone of the uterus on a scale of $1-5$. The uterine tone was assessed after the extraction of the baby on a scale of 1-5 as follows: Uterine tone 1. Atonic, 2. Partial, inadequate uterine contractions, 3.Adequate contractions, 4. Well contracted, 5.Very well contracted. All the consultant obstetricians participating in the study were trained regarding the assessment of the tone of the uterus to give a uniform interpretation of the scale.

Table 3 Comparison of Pre-Operative (Pre-Op) and Post Operative (Post-Op) Hemoglobin in gm/dl and Difference in the Hemoglobin Levels in Group I and Group 2

\begin{tabular}{|c|c|c|c|c|c|c|c|c|}
\hline \multicolumn{2}{|l|}{ Parameters } & \multicolumn{2}{|c|}{ Group I } & \multicolumn{2}{|c|}{ Group 2} & \multirow[t]{2}{*}{ p value* } & \multicolumn{2}{|c|}{ 95\% Confidence Interval } \\
\hline & & Mean & SD & Mean & SD & & Lower Bound & Upper Bound \\
\hline \multirow[t]{2}{*}{ Hemoglobin in gm/dl } & Pre-Op & 11.15 & 1.12 & 11.17 & 1.36 & 0.903 & -0.33 & 0.29 \\
\hline & Post-Op & 10.18 & 1.27 & 9.49 & 1.14 & $<0.001 *$ & 0.39 & 0.99 \\
\hline Difference in the hemoglobin levels in gm/dl & & 0.97 & 0.70 & 1.68 & 1.20 & $<0.001 *$ & -0.95 & -0.46 \\
\hline
\end{tabular}

Note: *If the $\mathrm{p}$-value is equal to or lesser than 0.05 then the result is considered to be statistically significant. 
Table 4 Comparison of Heart Rate, Systolic Blood Pressure, Diastolic Blood Pressure and SPO2 Between Group I and Group 2

\begin{tabular}{|c|c|c|c|c|c|c|c|c|}
\hline \multicolumn{2}{|l|}{ Parameters } & \multicolumn{2}{|c|}{ Group I } & \multicolumn{2}{|c|}{ Group 2} & \multirow[t]{2}{*}{ p value* } & \multicolumn{2}{|c|}{ 95\% Confidence Interval } \\
\hline & & Mean & SD & Mean & SD & & Lower Bound & Upper Bound \\
\hline \multirow[t]{4}{*}{ Heart rate } & $\mathrm{I} \min$ & 92.6 & 20.3 & 90.2 & 22.8 & 0.407 & -3.3 & 8.2 \\
\hline & $3 \min$ & 94.2 & 22.3 & 91.3 & 19.7 & 0.310 & -2.8 & 8.8 \\
\hline & $5 \mathrm{~min}$ & 94.9 & 16.9 & 92.8 & 20.9 & 0.433 & -3.1 & 7.3 \\
\hline & $10 \mathrm{~min}$ & 90.1 & 56.4 & 90.1 & 19.8 & 0.318 & -2.5 & 7.6 \\
\hline \multirow[t]{4}{*}{ Systolic pressure } & $I \min$ & 118.2 & 17.7 & 116.3 & 16.9 & 0.423 & -2.7 & 6.5 \\
\hline & $3 \mathrm{~min}$ & 116.9 & 18.5 & 114.2 & 18.3 & 0.296 & -2.4 & 7.7 \\
\hline & $5 \mathrm{~min}$ & 115.0 & 15.6 & 112.6 & 15.7 & 0.265 & -1.9 & 6.7 \\
\hline & $10 \mathrm{~min}$ & 116.2 & 15.7 & 114.1 & 14.1 & 0.269 & -1.6 & 5.9 \\
\hline \multirow[t]{4}{*}{ Diastolic blood Pressure } & $I \min$ & 73.9 & 14.5 & 71.8 & 13.7 & 0.274 & -1.7 & 5.9 \\
\hline & $3 \mathrm{~min}$ & 70.9 & 15.1 & 70.0 & 13.9 & 0.683 & -3.2 & 4.8 \\
\hline & $5 \mathrm{~min}$ & 70.0 & 13.9 & 67.2 & 12.4 & 0.121 & -0.8 & 6.5 \\
\hline & $10 \mathrm{~min}$ & 72.3 & 13.0 & 70.7 & 11.2 & 0.318 & -1.5 & 4.6 \\
\hline \multirow[t]{4}{*}{ SPO2 } & $I \min$ & 99.4 & 1.3 & 99.1 & 2.2 & 0.118 & -0.1 & 0.9 \\
\hline & $3 \mathrm{~min}$ & 99.3 & 2.1 & 98.9 & 2.2 & 0.238 & -0.2 & 0.9 \\
\hline & $5 \mathrm{~min}$ & 99.2 & 1.6 & 108.1 & 90.7 & 0.308 & -26.2 & 8.3 \\
\hline & $10 \mathrm{~min}$ & 99.0 & 1.6 & 98.4 & 8.2 & 0.424 & -0.9 & 2.1 \\
\hline
\end{tabular}

Note: *If the p-value is equal to or lesser than 0.05 then the result is considered to be statistically significant.

Need for additional uterotonics. If there is excessive bleeding or if the uterus is not adequately contracted then additional uterotonics were administered.

Need for blood transfusions. If the blood loss was an amount that causes hemodynamic instability then blood transfusion was done.

\section{Adverse Effects}

Adverse effects of the drug were noted, eg nausea, vomiting, etc.

\section{Statistical Analysis}

All characteristics were summarized descriptively. For continuous variables, the summary statistics of mean \pm standard deviation (SD) were used. For categorical data, the number and percentage were used in the data summaries and diagrammatic presentation. Chi-square $(\chi 2)$ test was used for the association between two categorical variables. If the p-value was and lesser than 0.05 , then the results were considered to be statistically significant otherwise it was considered as not statistically significant. Data were analyzed using SPSS software v.23.0 and Microsoft office 2010.

\section{Results}

During the study period, a total of 1787 patients were admitted to the labor ward, and 885 underwent cesarean section. A total of 250 women met the inclusion criteria. These 250 participants were randomized to 125 participants each in group, namely, Group 1 and Group 2, respectively.

Table 5 Comparison of ECG Changes, Adverse Effects and Use of Additional Uterotonics Between Group I and Group 2

\begin{tabular}{|l|l|l|l|l|l|}
\hline \multirow{2}{*}{ Parameter } & \multicolumn{2}{|l|}{ Group I } & \multicolumn{2}{l|}{ Group 2 } & p value* \\
\cline { 2 - 6 } & N & $\%$ & N & $\%$ & \\
\hline ECG lead changes & & & & & \\
I MIN & 0 & $0.0 \%$ & 0 & $0.0 \%$ & - \\
3 MIN & 0 & $0.0 \%$ & 0 & $0.0 \%$ & - \\
5 MIN & 0 & $0.0 \%$ & 0 & $0.0 \%$ & - \\
IOMIN & 2 & $1.6 \%$ & 1 & $0.8 \%$ & $0.56 \mathrm{I}$ \\
\hline Adverse effect & & & & & \\
Tachysystole & 0 & $0.0 \%$ & 0 & $0.0 \%$ & - \\
Nausea & 4 & $3.2 \%$ & 0 & $0.0 \%$ & $0.15 \mathrm{I}$ \\
Uneasiness in the & $\mathrm{I}$ & $0.8 \%$ & 2 & $1.6 \%$ & $0.56 \mathrm{I}$ \\
chest/chest pain & & & & & \\
Headache & 0 & $0.0 \%$ & $\mathrm{I}$ & $0.8 \%$ & 0.478 \\
PPH & 0 & $0.0 \%$ & $\mathrm{I}$ & $0.8 \%$ & 0.478 \\
\hline Use of additional & & & & & \\
uterotonics & & & & & \\
Yes & 3 & $2.4 \%$ & 3 & $2.4 \%$ & - \\
No & 122 & $97.6 \%$ & 122 & $97.6 \%$ & \\
Total & 125 & $100.0 \%$ & 125 & $100.0 \%$ & \\
\hline
\end{tabular}

Note: *If the p-value is equal to or lesser than 0.05 then the result is considered to be statistically significant. 
Table 6 Comparison of the Uterine Tone Following the Extraction of the Baby Between Group I and Group 2

\begin{tabular}{|c|c|c|c|c|c|c|c|c|}
\hline \multicolumn{2}{|l|}{ Parameters } & \multicolumn{2}{|c|}{ Group I } & \multicolumn{2}{|c|}{ Group 2} & \multirow[t]{2}{*}{ p value* } & \multicolumn{2}{|c|}{ 95\% Confidence Interval } \\
\hline & & Mean & SD & Mean & SD & & Lower Bound & Upper Bound \\
\hline \multirow[t]{4}{*}{ Tone of the uterus } & I MIN & 3.46 & 0.58 & 3.29 & 0.79 & 0.056 & 0.00 & 0.34 \\
\hline & $3 \mathrm{MIN}$ & 4.03 & 0.66 & 3.86 & 0.70 & 0.052 & 0.00 & 0.34 \\
\hline & $5 \mathrm{MIN}$ & 4.58 & 0.54 & 4.25 & 0.66 & $<0.001 *$ & 0.18 & 0.48 \\
\hline & IOMIN & 4.93 & 0.29 & 5.10 & 3.63 & 0.607 & -0.81 & 0.47 \\
\hline
\end{tabular}

Note: *If the p-value is equal to or lesser than 0.05 then the result is considered to be statistically significant.

[Figure 1] Group 1 was given 3 IU Oxytocin IV bolus with 7 IU Oxytocin added to the fluid on flow. Group 2 was given 10 IU IV infusion. There was no significant difference between the age, parity, duration of married life and period of gestation between both the groups. [Tables 1 and 2]

Pre- and post-operative hemoglobin levels were measured and the difference was noted to assess the blood loss. The difference between the drop of pre and post-operative hemoglobin was $0.71 \mathrm{gm} / \mathrm{dl}$ which corresponds to $6.7 \%$ [Table 3].

There was no significant difference between the two groups with respect to the variable parameters, ie heart rate, blood pressure, ECG, SpO2 at 1, 3, 5 and 10 minutes after administration of the drug [Tables 4 and 5]. The tone of the uterus was assessed at $1,3,5$ and 10 minutes after administration of the drug and showed significance in Group I with a significant $\mathrm{p}$ value of $<0.001$ at 5 minutes [Table 6]. One patient in Group II had atonic PPH. Three patients needed additional uterotonics in both groups. There was only one case of blood transfusion in Group I which was with one pint of whole blood. Complications associated with the administration of the drug-like nausea, vomiting, tachysystole and headache were similar in both the groups.

\section{Discussion}

The difference in blood loss between the groups was lesser in the bolus with infusion group than in the Oxytocin infusion group. The difference in the hemoglobin drop was $6.7 \%$ less in the bolus with infusion group than in the infusion group. A large-scale study conducted in Egypt showed that IV Oxytocin bolus was more effective than IV infusion or IM injections without any significant adverse effects. ${ }^{4}$ Other studies have shown that there is less blood loss when Oxytocin bolus is used. However, the adverse effects seen with IV bolus Oxytocin are more with doses of $10 \mathrm{IU}$ or $5 \mathrm{IU}^{18}$ In our study, there were no statistically significant adverse effects of the bolus Oxytocin with respect to ECG, hemodynamic, SPO2, uterine tachysystole, nausea, uneasiness in the chest/chest pain, headache or PPH. Studies conducted with the use of 5 IU have shown significant hemodynamic changes. ${ }^{20}$ However, doses of 3 IU have not shown to cause statistically significant hemodynamic changes. ${ }^{4}$ Various studies have used higher doses of Oxytocin infusion of $40 \mathrm{IU} .^{21}$ This would lead to excessive use of Oxytocin which may be unnecessary and would lead to extra cost. Our study used $10 \mathrm{IU}$ in all that would make it more cost-effective, with less adverse effects, without causing an increase in postpartum hemorrhage. Uterine tone was better at $5 \mathrm{~min}$ in the bolus group. Similar results have been seen in other studies with $3 \mathrm{IU} .{ }^{4}$ An adequate tone of the uterus would prevent the inadvertent use of additional oxytocics. As the WHO recommends only 10IU in either IV or IM route, our study has used $10 \mathrm{IU}$ though in a different proportion. ${ }^{13}$ Since this route has shown to be more effective without increasing the requirement of Oxytocin or the cost of treatment, we recommend this dose as an alternative to the standard protocol of 10 IU Oxytocin infusion.

\section{Conclusion}

Intravenous bolus of 3 IU with 7 IU infusion of Oxytocin is as safe as and more effective than intravenous infusion of10 IU of Oxytocin during cesarean section for the prevention of postpartum hemorrhage.

\section{Limitation of the Trial}

The trial did not differentiate primary and repeat cesarean sections. Neither the surgeons nor the anesthesiologist was blinded to the study.

\section{Data Sharing Statement}

The original data can be available by email at any time (Dr Rajasri G Yaliwal ryaliwal@bldedu.ac.in and Dr Aruna M Biradar aruna.biradar@bldedu.ac.in) 


\section{Acknowledgments}

I would like to thank all the Obstetricians, Anesthesiologists and postgraduate residents of obstetrics and anesthesiology of BLDE (DU) Shri BM Patil Medical College, Hospital and Research Center who played a vital role in this study.

\section{Funding}

No external funds were derived. This study has been internally funded by BLDE (Deemed to be University), Vijayapura, Karnataka India.

\section{Disclosure}

The authors report no conflicts of interest.

\section{References}

1. Adnan N, Boland F, Murphy DJ. Intramuscular Oxytocin versus intravenous Oxytocin to prevent postpartum haemorrhage at vaginal delivery (LabOR trial): study protocol for a randomised controlled trial. Trials. 2017;18(1):541. doi:10.1186/s13063-017-2269-9

2. Balki M, Erik-Soussi M, Kingdom J, Carvalho JC. Comparative efficacy of uterotonic agents: in vitro contractions in isolated myometrial strips of labouring and non-labouring women. Can J Anaesth. 2014;61 (9):808-818. doi:10.1007/s12630-014-0190-1.

3. Yaliwal R, Bidri S, Navani A. A randomized controlled trial of sub-

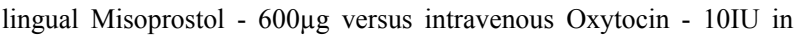
prevention of post partum hemorrhage during cesarean section. International Journal of Reproduction, Contraception, Obstetrics and Gynecology. 2019;8(10):3865-3869. doi:10.18203/ 2320-1770.ijrcog20194206

4. Charles D, Anger H, Dabash R. Intramuscular injection, intravenous infusion, and intravenous bolus of Oxytocin in the third stage of labor for prevention of postpartum hemorrhage: a three-arm randomized control trial. BMC Pregnancy Childbirth. 2019;19:38. doi:10.1186/ s12884-019-2181-2

5. Derbel M, Mekki D, Riahi A, Dimassi K, Mebazaa MS, Gara MF. Comparison of two Oxytocin administration protocols in elective cesarean section: 5iu versus 10 iu. Tunis Med. 2016;94(4):253-258.

6. Butwick* J, Coleman L, Cohen SE, Riley ET, Carvalho B. Cohen et al Minimum effective bolus dose of Oxytocin during elective Caesarean delivery. Br J Anaesth. 2010;104(3):338-343. doi:10.1093/bja/aeq004

7. Stephens LC, Bruessel T. Systematic review of Oxytocin dosing at caesarean section. Anaesth Intensive Care. 2012;40(2):247-252. doi:10.1177/0310057X1204000206

8. Elbourne DR, Prendiville WJ, Carroli G, Wood J, McDonald S. Prophylactic use of Oxytocin in the third stage of labor. Cochrane Database Syst Rev. 2001;4:CD001808.
9. Lokugamage AU, Paine M, Bassaw Balroop K, Sullivan KR, Refaey HE, Rodeck $\mathrm{CH}$. Active management of the third stage at caesarean section: a randomised controlled trial of misoprostol versus syntocinon. Aust N Z J Obstet Gynaecol. 2001;41:411-414. doi:10.1111/j.1479-828X.2001.tb01319.x

10. Munn MB, Owen J, Vincent R, Wakefield M, Chestnut DH, Hauth JC. Comparison of two Oxytocin regimens to prevent uterine atony at cesarean delivery: a randomized controlled trial. Obstet Gynecol. 2001;98:386-390.

11. National Collaborating Centre for Women's and Children's Health. Caesarean section. Clinical Guideline. 2004. RCOG Press.

12. Cotter A, Ness A, Tolosa J. Prophylactic Oxytocin for the third stage of labor. Cochrane Database Syst Rev. 2001;4:CD001808.

13. Begley CM, Gyte GM, Murphy DJ, Devane D, McDonald SJ, McGuire W. Active versus expectant management for women in the third stage of labor. Cochrane Database Syst Rev. 2010;7:CD007412.

14. Sheehan SR, Montgomery AA, Carey M, McAuliffe FM, Eogan M, Gleeson R, Geary M, Murphy DJ; ECSSIT Study Group. Oxytocin bolus versus oxytocin bolus and infusion for control of blood loss at elective caesarean section: double blind, placebo controlled, randomised trial. BMJ. 2011;343:d4661. doi:10.1136/bmj.d4661.

15. Mockler JC, Murphy DJ, Wallace EM. An Australian and New Zealand survey of practice prendiville, W.O.C., M., Active management of the third stage of labor. In: C B, L L, G K, A B, L M, Karoshi, editors. A Textbook of Postpartum Hemorrhage. 1ed ed. Duncow: sapiens publishing; 2006:462.

16. Gibbens D, Boyd NRH, Crocker S, et al. The circulating levels of Oxytocin following intravenous and intramuscular administration of Syntometrine. J Obstet Gynaecol Br Commonw. 1972;79(7):644-646. doi:10.1111/j.1471-0528.1972.tb14215.x

17. Breathnach F, Geary M. Standard medical therapy. In: B-Lynch C, Keith LG, Lalonde AB, aroshi M, editors. A Textbook of Postpartum Hemorrhage: A Comprehensive Guide to Evaluation, Management and Surgical Intervention. 1st edn ed. Duncow, Kirkmahoe, Dumfriesshire, UK: Sapiens Publishing; 2006.

18. Thomas JS, Koh SH, Cooper GM. Haemodynamic effects of Oxytocin given as i.V. Bolus or infusion on women undergoing caesarean section. Br J Anaesth. 2007;98(1):116-9. 256-262. doi:10.1093/bja/ael302

19. Schulz KF, Altman DG, Moher D. Updated Guidelines for Reporting Parallel Group Randomised Trials. PLoS Med. 2010;7(3):e1000251. https://journals.plos.org/plosmedicine/article.

20. Tandon R, Khan TA, Mehrotra S. Oxytocin given as IV bolus versus IV infusion in women undergoing caesarean section- a randomised, controlled, double-blind study. J Evolution Med Dent Sci. 2018;7 (11):1423-1425. doi:10.14260/jemds/2018/323

21. Mathe P, Kale S, Batra A, Batra A, Aggrawal S, Nagarajappa A. Intravenous Oxytocin bolus and infusion versus infusion alone on the blood loss during caesarean section. Int J Reprod Contracept Obstet Gynecol. 2019;8:4824-4828. doi:10.18203/2320-1770.ijrcog20195328
The International Journal of Women's Health is an international, peerreviewed open-access journal publishing original research, reports, editorials, reviews and commentaries on all aspects of women's healthcare including gynecology, obstetrics, and breast cancer. The manuscript management system is completely online and includes a very quick and fair peer-review system, which is all easy to use. Visit http://www.dovepress.com/testimonials.php to read real quotes from published authors. 